\title{
A Global Capability Framework: Reframing public relations for a changing world
}

\section{Introduction}

It is a truism to state that public relations is practiced in an increasingly globalised world and is globalising. One of the many resultant challenges facing individuals and the professional bodies representing the profession ${ }^{1}$ is the lack of an attendant global benchmark so that practitioners can share a common understanding of their current roles and duties, can recognise and aspire to best practice within their own and other contexts and plot a course for professional development.

The Global Alliance $(G A)^{2}$ is the worldwide confederation of professional bodies in public relations and communication management with members from all permanently inhabited continents. In 2014, it recognised the need for such a benchmark and embarked upon what has been a four year journey to develop a Global Capability Framework which takes into account the needs of the profession both now and into the future (see https://www.globalalliancepr.org/capabilitiesframeworks/ for details of the origins of the whole project).

The term public relations describes a range of functions in different countries. Its use is not ubiquitous and other phrases such as organisational communication, corporate communication, communication management and strategic communication are used almost synonymously (Christensen \& Cornelissen, 2011; Cornelissen, 2017; Heath \& Gregory, 2015; Hallahan, Holzhausen, van Ruler, Vercic \& Sriramesh, 2007). This ambiguity makes the task of researching and developing a Global Capability Framework for the profession a complex one, since not only are terms used differently, but the whole orientation of the field is contested, with some believing it should have an organisational focus and others seeing it within a social and cultural context (Gregory, 2012; Edwards, 2018).

In response to the call from GA to try to establish what was extant in competency and capability frameworks, a key study was undertaken from 2014 to 2016 to produce what became known as the Global Body of Knowledge (GBOK) (Global Alliance, 2016a). This study combined descriptions of public relations work from 31 sources such as existing professional body competency frameworks and academic studies, and organised them into Knowledge, 
Skills, Attributes and Behaviours (KSAB) required at junior, middle and senior levels of practice (Manley \& Valin, 2017). While this was widely welcomed as a move forward in helping set boundaries for the profession, others in the GA-affiliated professional bodies found the lists too extensive, cumbersome to use practically and, because they were constructed largely from Western sources, culturally insensitive (discussed in more detail below).

In response, the GA expressed the desire for a framework that was of more utility to the global community. As a result a nine-country ${ }^{3}$ academic research partnership was created representing institutions in seven continents (Asia, Scandinavia, Europe, Africa, Australasia, North America, South America) who agreed to work with their national and regional professional associations and employers on a second research project.

The brief from the GA was that the research should meet four criteria: offer practical value to GA affiliated professional bodies and their members, worldwide; reflect cultural and regional variations in public relations as a global profession; be forward looking in its approach; and meet academic standards for rigour.

This paper outlines the results for this second project, the research phase for which was concluded in 2018.

\section{Literature Review}

Given space restraints, this literature review is not exhaustive, but sets the backcloth for the research. The purpose of the review was not to identify gaps and areas for research per se, but to inform the thinking about and around the brief given by GA and to provide the basis for a way forwards that was sympathetic. The main theories from management, professionalism and public relations studies regarding the concepts of competence, competency and capability are reviewed. In the search for an approach that satisfied the brief given by GA more fully, the research team turned outside these fields and found that human development was enlightening. In particular, the works of Amartya Sen $(1993 ; 1999)$ and Martha Nussbaum (2000; 2002) were especially valuable. Therefore, Sen's (1999) Capability Approach (CA) is discussed as being fundamental to the conceptualisation and 
design of this research project and represents a new theoretical contribution to the public relations field.

\subsection{Management, and Professionalism approaches}

Management approaches often consider the topic of competence from the perspective of Resource-Based Theory (RBT), with the seminal author, Barney (1997), suggesting that knowledge, information, capabilities, characteristics and organisational procedures are resources. Those resources that are valuable, rare, difficult to imitate and non- substitutable contributing to gaining and maintaining competitive advantage.

In short, the management literature presents two types of competences: distinctive and core. Distinctive competences are defined as the capabilities that an organisation possesses that set it apart from its competitors, providing the basis for competitive advantage (Dosi \& Teece, 1998; Hall, 1992). Core competences are the collective learning in the organisation, especially how to coordinate diverse production skills and integrate multiple streams of technologies to deliver organisational objectives (Prahalad \& Hamel, 1990).

The word competences is also applied at the individual level and a number of frameworks for understanding, benchmarking and setting standards for practice have developed. Traditionally, these have tended to be descriptions of tasks - to ascertain professional expertise; or references to a body of knowledge - to assist with knowledge acquisition and curriculum design. They are often organised by level of seniority for job descriptions or level of degree for educational purposes. In this case they are the measurable, observable behaviours that help define the person and their desired contribution to the organisation. When individuals master these behaviours or competencies, they can be regarded as competent to perform their role. Behaviours are widely used in human resource management as a means of matching organisational needs in recruiting appropriate staff (Bartram, 2004, 2005). This thinking is supported by the Chartered Institute of Personnel and Development in the UK who state "Competency frameworks, when done well, can increase clarity around performance expectations and establish a clear link between individual and organizational performance" (CIPD, 2017, p.1). The purpose of these frameworks appears to be overtly instrumental and designed to achieve organisational 
objectives, performance and productivity with little reference to the needs or desires of individuals.

Some occupational and management consultants have evolved sophisticated frameworks for assessing competency requirements and advising on recruitment strategies. Importantly for this study, Ernst \& Young advises that leadership skills and competencies are evolving from traditional knowledge based approaches to 'softer' skills that have now become so critical to business leadership (Brooke \& Matthews, 2012).

Moving from competence to capabilities, the literature again identifies two categories: ordinary and dynamic capabilities. Ordinary capabilities can be described as those aspects that enable businesses to function in the short term (Winter, 2003), or to solve a problem (Zahra, Sapienza, \& Davidsson, 2006). Ordinary capabilities are about being efficient while, in contrast dynamic capabilities are about being entrepreneurial. A dynamic capability is defined as "the ability to achieve new forms of competitive advantage" (Teece, Pisano, \& Shuen, 1997, p. 515). The dynamic capability school focuses on the learning process within the firm, more precisely its abilities to reconfigure routines. Again, the ability to adapt to overcome market challenges is seen as a means to gain competitive advantage.

What is apparent from an overview of the management literature is that there is a lack of clarity or agreement over words such as competence, competences, competencies and capability. Confusingly, some management scholars use mixed descriptors at both organisational and individual levels. For example, Mulder (2001) proposes a working definition for competence, as the capability of a person or an organisation to reach specific achievements. For Mulder "personal competencies comprise integrated performance oriented capabilities, which consist of clusters of knowledge structures and also cognitive, interactive, affective and where necessary psychomotor capabilities, and attitudes and values, effectively functioning in a certain profession, organisation, position or role" (2001, p.152).

In the rich field of professionalism and professional competence studies, the literature is often based in thinking about qualifications and curriculum development. Stan Lester (2016), who advises professions across Europe on competency and capability frameworks, distinguishes between the 'internal' approach to competence where attributes are located 
in the competent person and the 'external' approach where the needs of the organisation or profession drive the framework. Lester (2014) cites Eraut and du Boulay's (2000) description of competency, which is about the ability to perform tasks and roles and to an expected standard, while the International Standards Organisation (ISO) (2012) defines it as "ability to apply knowledge and skills to achieve intended results". Lester (2016) also found that the 'internal', attributes-based approach has wider usage in North America, particularly in developing professional educational programmes, whereas Europeans prefer the 'external', activity-based approach which defines competency in outcomes rather than personal qualities.

Competence and competency frameworks have evolved since the growth of vocational education during the second half of the twentieth century (Lester, 2014), whereby professional bodies and educational providers designed curricula to meet the specific needs of employers. While this linkage persists in some professions, where technical knowledge is a requirement to practice (for example, medicine), in many emerging professions the ability to perform a set of tasks has given way to more generic abilities, such as agility or problem solving. The more 'technical' professions too are recognising the need for generic abilities that characterise the 'professional' whatever their profession and embrace the emerging concept of the 'capable practitioner' (Stephenson, 1998). In such approaches, capabilities are often expressed in terms of specific aspects of the profession, plus the more generic aspects mentioned above (Lester, 2016). Examples of professions adadopting this approach include UK bodies such as the Landscape Institute, the Institute for Conservation and the Engineering Council, and it lies at the heart of on-going pan-European discussions on professional standards (Lester, 2016).

Scholars in education and professionalism are also expressing a growing preference for such capability approaches. Stephenson \& Yorke (2013) draw a distinction between what one is able to do in the present and what an individual or occupation might be capable of in the future. Lester (2016) sees this as the holistic approach, tying together the aspirations of the individual, the profession and the contextual drivers for the profession.

This 'turn' towards capability in the professional literature is important for the research outlined in this paper because it moves towards convergence with the human development literature described below. Crucially it focuses not only on competencies and competence, 
but also on attributes such as open-mindedness, adaptability, an ability to deal with the unfamiliar and unpredictable and to exercise judgement (Nagaragan \& Prabhu, 2015; Cairns, 2000; Fraser \& Greenhalgh, 2001; Lester, 2014). As Lester captures it "the capability approach is generally perceived as an open model, supporting continuous development: there is a spectrum of capability as opposed to either a threshold of 'capable or not capable' or a neat scale of progressively increasing capacity" (Lester, 2014, p.38). Thus, capability also embraces the possibility of professionals being equipped to deal with a very different future in which roles will be subject to 'disruptive change' and where it is virtually impossible to describe what jobs will be like when, for example, re-shaped by artificial intelligence.

\subsection{Public relations approaches}

In the past, competency has been used in public relations to understand and describe levels of proficiency, helping shape professional entry requirements and recognise levels of seniority. This is consistent with traditional management uses of the term. As in the management field, competency, competency and capability are widely used but not always defined. The confusion in terminology is highlighted by Gregory (2008) and Pieczka (2016) who notes confusion around the words and concepts of competence and competency (which she uses synonymously) and skill.

Gregory (2008), who developed the first European-based competency framework for Board level public relations practitioners, uses Bartram's (2006) Universal Competency Framework (UCF) as a base. UCF is organised around eight sets of desirable management behaviours (or competencies): leading and deciding; supporting and cooperating; interacting and presenting; analysing and interpreting; creating and conceptualising; organising and executing; adapting and coping; enterprising and performing.

The ECOPSI project developed a framework for researching public relations roles, structured around six clusters identified in the Netherlands by Logeion (2012), namely: analysing, counselling, creating, organizing, guiding/supporting, and managing. As in Gregory's work, ECOPSI moves away from a focus on tasks and justifies this because "The rigidity of 'labels' 
and 'levels' does not allow practitioners to adapt to changes, nor does it allow the industry to adapt." (Tench et al., 2013, p.14).

In terms of scale, the largest work in mapping public relations is GBOK (Global Alliance, 2016) mentioned earlier. It has been widely welcomed as setting out the parameters of the profession, and has influenced curriculum development (Manley \& Valin, 2017), however it was regarded as incomplete in that it did not encompass enough cultural and geographic difference and was too normative and descriptive. In particular, leaders from Asia, parts of Africa and South America found GBOK too Western-centric and voiced this view at the World Public Relations in Toronto in 2016 and in written feedback (Global Alliance, 2016b). Moreover, being drawn from existing frameworks, many of which were several years old, GBOK described current and past tasks rather than anticipating developments in practice and hence tended to omit a conceptualisation that embraced a different type of future work (Global Alliance, 2016b). Its structure, around levels of seniority and discrete tasks contributed to a lengthy and difficult to use directory of competences.

Pieczka (2016) summarises a literature review commissioned by the Chartered Institute of Public Relations under the name of the Future Skills project looking at knowledge, skills and competences. She proposes a conceptual model consisting of a four-part, geared wheel where all parts can be rotated independently to align to the other parts in any combination. The four parts are: meta-level theories, two wheels of substantive concepts, and 'tools'. Thus, ethics (meta-level theory) can be articulated with substantive concepts such as reputation, responsibility, values and stakeholders, which in turn use a range of tools such as issues management, CSR, Stakeholder management and transparent communication.

Overall, the public relations literature reviewed is not overtly sensitive to regional and cultural differences and may result in describing the 'ideal' practitioner as an aggregate of the existing occupational group comprising those who gain the highest level of attention, often in Western and economically developed countries. There is also the danger, common in vocational education, of catering for employers' perceived and current needs rather than anticipating the future and preparing for change at individual, professional and organisational levels. 
Other perspectives are also absent from all the literature discussed: human agency; the element of choice; and what might prevent a person's or profession's capability from being realised. These ideas lie at the heart of Amartya Sen's (1999) Capability Approach and the next section summarises this work.

\subsection{Sen's Capability Approach (CA)}

The literature from human development emerges from philosophical and economic approaches to well-being rather than being driven primarily by management considerations of organisational advantage or efficiency and effectiveness.

The Capability Approach (CA) was developed by the Nobel prize-winning economist Amartya Sen $(1993 ; 1999)$ with significant contributions from the philosopher Martha Nussbaum (2000, 2002). It has gained currency as an applied approach to development and global sustainability in recent years (Robeyns, 2006). It has also been applied to educational development, health issues and professional development (see below). Its core concepts are summarised by Walker and Unterhalter (2007, pp. 2-7) as threefold: the centrality of a person's (or group's) well-being to human flourishing; distinctions between the capacity to flourish and the functioning or demonstration of valued achievements; and the freedom to choose what is valued. These concepts are unpacked below.

\section{a) Human well-being}

Sen and Nussbaum have, from different perspectives, sought to create schema for measuring and evaluating human development across global variables. Sen moved away from measuring modernisation through Gross National Product to developing capability variables that take into account resources and value, recognising that humans make choices within what is actually available in order to realise their own desired outcomes.

While Sen did not specify what constitutes human flourishing, Nussbaum (2000, cited in Bates, 2007, p. 144) suggests a list of ten key qualities; life; bodily health; bodily integrity; senses, imagination and thought; emotion; practical reason; affiliation; other species; play; and control over one's environment. Bates (2007) highlights the relevance of practical 
reason and affiliation for the application of this approach to educational leadership; and similar considerations apply to professional leadership in the communication field (see below). Others using the capability approach have modified this list to their fields of investigations, though a similar level of abstraction and fundamentalism is maintained.

b) Capabilities and functionings

Capabilities represent "a person's ability to do valuable acts or reach valuable states of being" (Sen, 1993, p.30). Sen defines capabilities as "alternative combinations of functionings the person can achieve, and from which he or she can choose one collection" (Sen 1993, p.31). It should be noted that the capabilities need to be valued by the person/group; the individual's desires are not the sole determinant. Thus, it balances utilitarian approaches which see individuals as means to an end (for example, as a means of achieving organisational objectives) with approaches that claim individual wishes should also be pursued. Robeyns (2005) calls this ethical individualism with the balancing components being the functionings or outcomes that are desired by wider society or group, whether organisational or professional.

Functionings are closer to competences, the behaviours or actions that indicate levels of achievement. They tend to be more detailed and descriptive than capabilities. Walker and Unterhalter (2007) in their application of this approach to education distinguish between reading or teaching literacy skills to children as functionings with the availability of reading materials and a culture that values education as essential to the capabilities. They note that functionings such as identical examination results may hide vastly different capabilities. The distinction between these two concepts, then, is crucial because not all persons or groups have the opportunity or resources to realise their capabilities.

\section{c) Agency and choice}

The CA also enables groups and individuals to construct, evaluate and prioritise what is of value to them, thus agency is vital. Gangas (2015) affirms that CA situates the agency of the individual in their institutional context. For public relations (and for any area), an 
investigation of the career choices made by an individual practitioner within the context of educational opportunities and preferred outcomes suggested by professional bodies or employers would be enlightening.

The CA's origins in global development policy, encourages new thinking about cultural and regional variations in public relations practice and values, economic variables such as access to resources, political context such as the ruling political philosophy and the level of press freedom, combined with freedom of choice around selection of capabilities. The reality is that practitioners choose career pathways that require emphasis on different combinations and depths of capabilities dependent on the context in which they work and their own desires for self-development. They become experts in some areas of practice, while less expert in others dependent on their circumstances and the requirements of their roles at any one time. Uniform progression from level to level across the range of competencies is not the lived reality of most practitioners. CA moves away from the notion of the homogenised practitioner defined by seniority levels with their defined lists of KSABs. However, it is important to state this does not imply that KSAB frameworks have no value, or that a 'free for all' is to be encouraged where practitioners pick and choose their capabilities and demand that these are recognised irrespective of the needs of their employers or the future well-being and development of the profession. What it does recognise is that variation across the globe and between employments and employers is not only to be expected, but welcomed as reflective of the richness and diversity of any professional group.

The CA approach marries well with more recent thinking from the professional literature in that it looks at notions of potential and is future oriented. A combination of resources, individual choices and an ability to make those choices, along with professional development that prepares practitioners for the future and not just the present, can lead to a human flourishing that is rewarding both for the individual, the professional group and employer. Thus, a capability framework that embraces these elements can build in a level of future-proofing that will serve the practitioner and the profession well. 
Importantly, the CA has been used as a methodology in empirical research across a range of fields, including global education practices (Walker \& Unterhalter, 2007); multi-national research into the development of midwifery as a profession in sub-Saharan Africa (McCarthy, Kelley, Verani, St. Louis, \& Riley, 2014); and nursing (O'Connell, Gardner, Coyer, Gardner, \& Coyer, 2014). It has also been foundational in communication research (Kleine, 2011), and Jacobson (2016) has recently argued that CA should be employed as an overarching conceptual framework in the field of communication for development and social change (CDSC) on the grounds that it is 'interdisciplinary, cosmopolitan and oriented to public communication' (Jacobson, 2016, p.789).

\subsection{Conclusions from literature review and research questions}

In summary, a number of points can be drawn from this literature review. First, management approaches to competency/capability frameworks are confused in terminology and have a tendency to be instrumental, taking the needs of the organisation as paramount. Resulting frameworks are often normative and descriptive.

Second, the professions and professional literature has moved away from KSAB based frameworks to embrace a more holistic capability approach that recognises the potential of all actors involved, not just their current performance. It also recognizes that capability prepares professionals for the future.

Third, the public relations literature reflects these confusions and has yet to fully embrace the concept of capability.

Fourth, Sen's Capability Approach embraces values, agency and choice and emphasises the potential, or future, of the individual or group. Nussbaum's Core Capability lists offer a way forward for building research that reflects varying needs and values in different populations. Fifth, there is a level of convergence in the professional and CA literature that points to a helpful way forwards.

In the context of the literature reviewed and given the brief from GA, three research questions were framed: 
RQ1. Is there a shared set of public relations capabilities that defines the profession globally?

RQ2. What, if any, are the variations by region/culture and by stakeholder groups?

RQ3. How can such a framework(s) be of practical value for professional development, at individual, national, regional and global levels?

To address these questions, the following methodology was implemented.

\section{Research Methodology}

The methodological approach was largely qualitative, with primary research being undertaken in the nine countries who took part in the study (Argentina, Australia, Canada, Singapore, South Africa, Spain, Sweden, UK, and USA). Three empirical data collection methods were used with the lead researchers based in the UK developing and testing the research instruments and then sharing them for piloting, adaptation and use in the other eight countries. In all countries, a Delphi study was used to surface views from recognised experts on the capabilities of the professional community. This was followed in most countries by a survey and then focus group/individual interviews to test this expert view and explore wider perceptions of the initial findings in specific participant communities (see below for details). In total, there were nine Delphi studies (one in each country); 1079 survey responses and 33 focus groups. In two countries (South Africa and the USA), individual interviews were conducted instead of focus groups to provide additional validation to survey responses.

There were some variations in data collection to accommodate local needs and conditions. For example, the Swedish partner was satisfied by the outcome of two rounds of the Delphi research given detailed investigations on the topic had been conducted within the last 12 months. In Spain, an extended series of focus groups was conducted country-wide instead of a survey because capability is a new concept there and there were issues in obtaining the practitioner data base from the professional association. While the experienced research team acknowledge that allowing data collection variations is outside the strict parameters 
of scientific rigour, it is within the spirit of CA. All variations were discussed and agreed by the team.

Table 1 provides details of the data collection undertaken in each country.

\begin{tabular}{|c|c|c|c|c|}
\hline Country & $\begin{array}{l}\text { Stage } 1 \\
\text { Delphi/Rounds }\end{array}$ & $\begin{array}{l}\text { Stage } 2 \\
\text { Survey/ } \\
\text { Respondents }\end{array}$ & $\begin{array}{l}\text { Stage } 3 \\
\text { FGD/Interviews } \\
\text { No./Participants }\end{array}$ & $\begin{array}{l}\text { Comments and } \\
\text { variations by country }\end{array}$ \\
\hline Argentina & $\begin{array}{l}\text { Yes: } 3 \text { rounds } \\
\text { (17 participants first } \\
\text { round, } 14 \text { final round }\end{array}$ & Yes 127 & 3 FGDs: 27 & $\begin{array}{l}\text { Regional FGDs held to } \\
\text { ensure geographical } \\
\text { reach }\end{array}$ \\
\hline Australia & $\begin{array}{l}\text { Yes: } 3 \text { rounds } \\
\text { (19 participants first } \\
\text { round, } 14 \text { final round) }\end{array}$ & Yes: 96 & 7 FGDs; 32 & $\begin{array}{l}\text { Online FGDs increased } \\
\text { geographical reach }\end{array}$ \\
\hline Canada & $\begin{array}{l}\text { Yes: } 4 \text { rounds } \\
\text { (14 participants all } \\
\text { rounds) }\end{array}$ & Yes: 115 & 5 FGDs: 18 & $\begin{array}{l}\text { Online FGDs increased } \\
\text { geographical reach }\end{array}$ \\
\hline Singapore & $\begin{array}{l}\text { Yes: } 3 \text { rounds } \\
\text { (17 participants all } \\
\text { rounds) }\end{array}$ & Yes: 44 & 2 FGDs: 23 & $\begin{array}{l}\text { Additional Questions in } \\
\text { Stages } 2 \& 3 \\
\text { regarding } \\
\text { accreditation }\end{array}$ \\
\hline South Africa & $\begin{array}{l}\text { Yes: } 3 \text { rounds } \\
\text { ( } 20 \text { participants first } \\
\text { round, } 18 \text { final round }\end{array}$ & Yes: 137 & $\begin{array}{l}\text { No FGDs: } 3 \\
\text { interviews }\end{array}$ & $\begin{array}{l}\text { Some changes to } \\
\text { questionnaire }\end{array}$ \\
\hline Spain & $\begin{array}{l}\text { Yes: } 3 \text { rounds } \\
\text { (17 participants first } \\
\text { round, } 14 \text { final round) }\end{array}$ & No & 7 FGDs: 56 & $\begin{array}{l}\text { Professional body } \\
\text { mainly consists of } \\
\text { senior practitioners }\end{array}$ \\
\hline Sweden & $\begin{array}{l}\text { Yes: } 2 \text { rounds } \\
\text { (15 participants first } \\
\text { round, } 12 \text { second round) }\end{array}$ & No & 2 FGDs: 10 & $\begin{array}{l}\text { Data from parallel } \\
\text { communication survey } \\
\text { mined for relevance }\end{array}$ \\
\hline UK & $\begin{array}{l}\text { Yes: } 3 \text { rounds } \\
\text { (14 participants first } \\
\text { round, } 11 \text { final round) }\end{array}$ & Yes: 139 & 7 FGDs: 45 & \\
\hline USA & $\begin{array}{l}\text { Yes: } 3 \text { round } \\
\text { ( } 9 \text { participants in all } \\
\text { rounds) }\end{array}$ & Yes: 401 & $\begin{array}{l}\text { No FGDs: } 4 \\
\text { interviews }\end{array}$ & $\begin{array}{l}\text { Questions in Stage } 3 \\
\text { differed from } \\
\text { guidelines }\end{array}$ \\
\hline
\end{tabular}

Table 1: Summary of data collection by country - including variations

The research was designed in four stages, as is further described below, the first three to reflect the research questions and to ensure that each stage added depth and validation to the results from previous stages. The fourth was an analysis and synthesis of the results of the earlier stages to create the Global Capability Framework. 


\subsection{Population and sampling}

The target populations were public relations practitioners and academics, and employers of public relations and communication management staff in the nine participant countries. Most research partners contacted practitioner populations through affiliated and other professional bodies. Purposive and snowballing sampling was used for academic participants: researchers worked with professional bodies to identify individuals who lead courses. In addition, the researchers are well-connected in their national academic communities and were able to select fellow academics knowledgeable of curriculum design and of practice. These fellow academics were in turn able to recruit others they deemed appropriate. Employers were reached though professional associations and through personal contact and were identified as engaged with relevant professional bodies. This engagement was regarded as important since it signalled a keenness for the professional development and standing of public relations practitioners in their organisations, a factor confirmed during interviewing. Employers included the public sector in national government, local government and state-owned organisations; the private sector in primary, manufacturing and service industries and from a range of sectors, such as mining, banking, automotive, health and IT, and small and medium sized enterprises. A number of global and national public relations consultancies also participated.

\subsection{Methods}

The individual methods are now described detail below and were designed to address the research questions as outlined earlier.

\section{Stage 1: RQ1 - Is there a shared set of PR capabilities that defines the profession globally?}

The first step in building a capability framework is to generate the capabilities to be tested in wider populations (Walker, 2007; Kleine, 2011; McCarthy, Kelley, Verani, St. Louis \& Riley, 2014). In CA-driven projects this often starts with the Delphi method. For example, Cosic, Shanks and Maynard (2015) consulted academics and practitioners in their field (business analytics) to ensure a rich and valid capability set for the main project. Delphi is a rigorous research method where the researcher facilitates a process whereby experts, anonymous to 
each other and without consultation, set down and review their opinions on a topic over a number of rounds (often three) until consensus is reached.

To answer RQ1, each country assembled a Delphi panel of expert practitioners, academics and employers to volunteer their view of the profession's capabilities. These statements represent the foundational descriptors of the field that cannot be further reduced and which in total scope its range and boundaries.

Rationale for use of this method: Delphi study allowed each country to consult its own expert practitioners, academics and employers to generate a capability set. A number of key characteristics pertain to Delphi studies that were regarded as important for this study: anonymity; no need for face to face meetings; freedom from dominant personalities and social pressure; ability to participate irrespective of geography; ability to participate irrespective of time constraints; iteration with controlled feedback leading to reflective responses; statistically measurable group findings (Cosic, Shanks \& Maynard, 2015; Sourani \& Sohail, 2015).

\section{Stage 2: RQ2 - What, if any, are the variations by region/culture and by stakeholder groups?}

Next, the research sought to discover whether a broader range of practitioners and academics agreed with the experts and if these groups had different priorities. The results from each country can then be compared to see if different regions prefer some capabilities to others. This was achieved in most countries by conducting an online-survey, with the support of the national professional body in each country. The survey also asked practitioners about what might help or hinder them achieve the capabilities that they ranked as important for their own future. Educators were asked what factors might impact the development of capability-based curricula.

The survey had 55 questions organised in five blocks. The first block focused on the importance of capabilities for the profession and the profile of the respondent. The second comprised questions for academics, the third had questions for practitioners with the fourth 
consisting of questions for employers. The last block comprised demographic questions. Skip logic ensured respondents were directed to the relevant blocks.

The data was coded, cleaned and analysed in each country. Simple numerical analysis was the starting point, but further analysis was completed depending on requirements including a one-way Analysis of Variance (ANOVA) using each capability as an independent variable and "practitioner, academic and employer" as a dependent variable; Shapiro-Wilk, to determine the normality of the dependents; Rosenberg self-esteem scale, to determine the reliability of the data; Cronbach's alpha, to assess consistency of the data; and the Mann-Whitney $U$ test to determine whether there was a difference between practitioners and academics in relation to their view of the importance of the capabilities. It is not within the scope of this paper to provide detailed comparisons between countries, but each country report with full data analysis is provided on the project website (University of Huddersfield, 2018).

Rationale for use of this method: In order to test the validity of the Delphi panel results with a wider population, it was decided that a structured questionnaire would facilitate a larger number of potentially more representative of responses, while placing some constraints on what had been noted in the pilot testing as a tendency to evangelise for a particular specialism or point of view. In addition to testing the validity of the initial capability statements emerging from the Delphi round, the research instrument was designed to reflect the importance of agency and choice, in line with the CA and to assist with 'futureproofing'. This required respondents to indicate future, desired achievements rather than present performance, and to identify what might help or hinder the achievement of those goals (Rea \& Parker, 1996).

\section{Stage 3: RQ3 - How can such a framework(s) be of practical value for professional development, at individual, national, regional and global level?}

The third stage consisted a series of focus groups and/or interviews with practitioners, academics and employers to further test the veracity of the findings, to discover what practical value might be gained from use of the Framework and to inform how it should be developed for optimum use. The purposeful sampling undertaken to identify recognised 
leaders in the academic, practitioner and employer communities, used screening criteria such as level of experience and involvement with the practitioner community (academics), seniority and positons occupied (practitioners) industry specialisation and size (employers). The professional associations assisted with identifying and organising the focus groups and interviews. A semi-structured interview protocol was developed to include discussion of the capabilities identified through the Delphi study and survey, how interviewees would rank the capabilities; how they might use them, obstacles and drivers for developing capabilities and continuing professional development provision. Thematic analysis was undertaken.

Rationale: Focus groups and interviews allow in-depth exploration of the topic and gains a more complete understanding of it. Although focus groups are not intended to generalize (Steward, Shamdasani \& Rook, 2007) they were useful to follow up issues raised in the first or second stage, collect impressions of the capabilities statements and stimulate discussion about its potential uses.

At the end of Stage 3, each country had a framework comprising a number of capability statements which in sum scoped and described the profession in their region in an irreducible form. Each capability statement was supported by a number of sub-capabilities which unpacked and explained their essence and essential characteristics.

\section{Stage 4 - Synthesis and creation of the Global Capability Framework}

Once the country results were collected, the international research team met in London for two days to compile the Global Capabilities Framework. Each country's capability statements were physically displayed in dis-aggregated form, without the sub-capabilities. The meaning and context for each country capability was discussed in detail, led by the researcher whose results were under discussion. Common capabilities were identified under broad headings and the statements re-combined with any duplications stripped out, but with the breadth of meaning captured.

From this and after the meeting, a document showing how capabilities could be clustered and identifying 'outliers' was circulated to the research team. This was the subject of two conference calls with the results of those discussions being documented and circulated. The 
process of conference calls and shared documents with multiple iterations was repeated to establish consensus on the sub-capabilities.

\section{Findings}

As described above, the Global Capabilities Framework emerged through synthesis of country-based research outcomes. Before compiling the final version, the research team were mindful of what had been discovered in the literature review, that is, capabilities are often expressed in terms of specific aspects of the profession and generic aspects of being a professional (Lester, 2016). Adapting this thinking, the research team developed Communication, Organisational and Professional categories for the 11 main capabilities as shown in Table 2.

Table 3 provides the full Global Capabilities Framework showing the 11 capabilities with their attendant sub-capabilities. 


\section{GLOBAL CAPABILITY FRAMEWORK FOR PUBLIC RELATIONS AND COMMUNICATION MANAGEMENT}

\section{Communication Capabilities}

To align communication strategies with organisational purpose and values

To identify and address communication problems proactively

To conduct formative and evaluative research to underpin communication strategies and tactics

To communicate effectively across a full range of platforms and technologies

\section{Organisational Capabilities}

To facilitate relationships and build trust with internal and external stakeholders and communities

To build and enhance organisational reputation

To provide contextual intelligence

\section{Professional Capabilities (those expected of any professional)}

To provide valued counsel and be a trusted advisor

To offer organisational leadership

To work within an ethical framework on behalf of the organization, in line with professional and societal expectations

To develop self and others, including continuing professional learning

Table 2. The three categories of capabilities within the Global Capability Framework 


\begin{tabular}{|c|c|}
\hline Capabilities & Sub Capabilities \\
\hline $\begin{array}{l}\text { To align communication strategies with } \\
\text { organisational purpose and values }\end{array}$ & $\begin{array}{l}\text { You set clear communication objectives that are aligned to organisational objectives and then see them through } \\
\text { You act as an architect of communication plans, enacting the purpose, values and policies of the organisation } \\
\text { You understand how communication can - and cannot - help an organisation realise its objectives }\end{array}$ \\
\hline $\begin{array}{l}\text { To identify and address communication } \\
\text { problems proactively }\end{array}$ & $\begin{array}{l}\text { You create short and long-term narratives to facilitate communication with multiple organisational stakeholders } \\
\text { You identify opportunities to design organisational communication, and outline core content } \\
\text { You develop integrated communication operations }\end{array}$ \\
\hline $\begin{array}{l}\text { To conduct formative and evaluative } \\
\text { research to underpin communication } \\
\text { strategies and tactics }\end{array}$ & $\begin{array}{l}\text { You use research to listen to and understand situations before, during and after communication and relationship-building activities } \\
\text { You manage research design, data collection and analysis to improve communication outcomes } \\
\text { You establish evaluation systems to demonstrate the impact of communication }\end{array}$ \\
\hline $\begin{array}{l}\text { To communicate effectively across a full } \\
\text { range of platforms and technologies }\end{array}$ & $\begin{array}{l}\text { You have command of communication specialties, such as investor relations, and understand the optimum channels for specific } \\
\text { stakeholders } \\
\text { You communicate effectively across paid, earned, shared and owned (PESO) channels } \\
\text { You have or can source strong written and visual skills to create and tell stories that engage and connect with diverse publics. } \\
\text { You synthesise complex concepts and convert them to simple, clear and relevant content }\end{array}$ \\
\hline $\begin{array}{l}\text { To facilitate relationships and build } \\
\text { trust with internal and external } \\
\text { stakeholders and communities }\end{array}$ & $\begin{array}{l}\text { You identify, analyse and listen to stakeholders and their communication needs } \\
\text { You develop stakeholder engagement strategies and partnerships that are mutually beneficial } \\
\text { You communicate sensitively with stakeholders and communities across a range of cultural and other values and beliefs }\end{array}$ \\
\hline $\begin{array}{l}\text { To build and enhance organisational } \\
\text { reputation }\end{array}$ & $\begin{array}{l}\text { You identify, analyse and strategically advise on key issues and risks for the organisation. } \\
\text { You help the organisation to define and enact its purpose and values } \\
\text { You help shape organisational culture and its processes } \\
\text { You understand and manage key intangible assets (e.g. brand, culture, sustainability) }\end{array}$ \\
\hline To provide contextual intelligence & $\begin{array}{l}\text { You see the bigger picture - socially, culturally, politically, technologically and economically } \\
\text { You identify strategic opportunities and threats, issues and trends } \\
\text { You operate in a connected world, demonstrating broad understanding of local and global diversity in culture, values and beliefs }\end{array}$ \\
\hline $\begin{array}{l}\text { To provide valued counsel and be a } \\
\text { trusted advisor }\end{array}$ & $\begin{array}{l}\text { You combine a long term perspective with the agility to manage crises } \\
\text { You offer strategic counsel to executive management, particularly regarding the interests of multiple stakeholders } \\
\text { You influence organizational decision-making and development } \\
\text { You negotiate with empathy and respect for all parties }\end{array}$ \\
\hline To offer organisational leadership & $\begin{array}{l}\text { You are part of or have access to the executive management team and help build internal alliances within the organization } \\
\text { You demonstrate communication leadership by encouraging management based on dialogue } \\
\text { You demonstrate business and financial acumen through sound knowledge of the organisation's business and core processes }\end{array}$ \\
\hline
\end{tabular}




\begin{tabular}{|c|c|}
\hline $\begin{array}{l}\text { To work within an ethical framework on } \\
\text { behalf of the organisation, in line with } \\
\text { professional and society's expectations }\end{array}$ & $\begin{array}{l}\text { You consider business objectives in the light of society's expectations } \\
\text { You clarify the consequences of a proposed action on others, ensuring potential outcomes are understood by decision-makers } \\
\text { You understand and apply ethical frameworks } \\
\text { You recognise and observe the societal obligations of professionals }\end{array}$ \\
\hline $\begin{array}{l}\text { To develop self and others, including } \\
\text { continuing professional learning }\end{array}$ & $\begin{array}{l}\text { You take responsibility for your own continuous professional development, through a range of activities including training and } \\
\text { education } \\
\text { You participate in industry events, represent the industry in public, and educate others on the role and value of public relations to } \\
\text { employers and clients } \\
\text { You are able to offer professional guidance which involves, motivates and contributes to personal and team development }\end{array}$ \\
\hline
\end{tabular}

Table 3: The full Global Capability Framework with sub-capabilities 
To illustrate the provenance of the final statements, one capability from the organisational category is provided in Table 4. It should be noted that not all the capabilities that were agreed were present in every country framework and the full extent of the discussion around each capability is impossible to capture in such a representation. The procedure was not a simple matter of disaggregation and re-aggregation, but one where the nuance of local context and meaning was discussed at length. Furthermore, every researcher involved was familiar with the profession beyond their countries of current domicile and there was agreement that the Global Capabilities Framework appeared representative beyond the nine countries directly involved. Subsequent exposure to the global practitioner community (for example at the World Public Relations Forum in Oslo, April 2018 and at the Public Relations Society of America International Conference in Austin, September 2018) has endorsed this view.

\section{Organisational}

CAPABILITY: To facilitate relationships and build trust with internal and external stakeholders and communities

\begin{tabular}{|l|l|}
\hline Source statements & Country \\
\hline $\begin{array}{l}\text { Analysing, identifying and negotiating with appropriate internal and } \\
\text { external stakeholders on their communication needs }\end{array}$ & Australia \\
\hline $\begin{array}{l}\text { To generate long-term relationships with publics/stakeholders based } \\
\text { on trust, effective communication and consensus, in order to rank } \\
\text { the organisation as a responsible social actor }\end{array}$ & Argentina \\
\hline $\begin{array}{l}\text { To manage relationships and build trust with stakeholders, internal } \\
\text { and external }\end{array}$ & Canada \\
\hline $\begin{array}{l}\text { To create good relationships with people at different levels in the } \\
\text { organization }\end{array}$ & Sweden \\
\hline $\begin{array}{l}\text { To build and manage relationships inside and outside the } \\
\text { organization }\end{array}$ & USA \\
\hline- & Singapore \\
\hline To contribute to stakeholders relationships management & Spain \\
\hline Working collaboratively with stakeholders, internal and external & UK \\
\hline $\begin{array}{l}\text { To manage relationships with stakeholders, internal and external } \\
\text { To assist organisations to be communicatively competent in } \\
\text { addressing community demands }\end{array}$ & South Africa \\
\hline
\end{tabular}

Table 4: Example of the provenance of an Organisational Capabilitiy

\section{Discussion}


The potential for extended discussion of the results is recognised, but to maintain the focus for this paper, it is structured around the three research questions.

\section{RQ1 Is there a shared set of PR capabilities that defines the profession globally?}

Through the research described above, a remarkably coherent and universally supported framework was created by the nine partner countries around the globe. The degree of convergence surprised the researchers, leading some to speculate whether the aspirational nature of capabilities elicited scripted responses. It was noted that most respondents, certainly from the practitioner and academic communities, were members of their professional body and committed to the profession and its development. As such, they engaged with other, often like-minded professionals in discussion about its status, the challenges and opportunities it faces and how it might develop into the future. There may be, therefore, a normative and aspirational 'group think' among these professional communities.

On the other hand, the use of the Delphi method, which elicits individual responses, would indicate that these are certainly the considered views of acknowledged leaders and experts in the field. By virtue of their position it would be expected that they are more independent of thought and not afraid to advance their own opinions. This was supported to an extent by survey respondents who often indicated their own lack of capability in areas they considered important for the profession (not covered in this paper), suggesting that they felt free to provide honest answers.

Whatever is the case, and only further research would determine this, the results have produced the first Global Capability Framework for public relations and communication management with a set of statements that define the scope and depth of the profession worldwide. As such it stands as a significant contribution to the body of knowledge in the field.

The breadth and depth of agreement regarding the core capabilities provides a valuable tool for practitioners, academics and professional bodies in building a global community. It points to the veracity of the GA's own initial thinking which prompted the project, that is that the impact of globalisation has led to commonalities of thinking and practice, and to the preservation of some differences important differences. Practical value is explored 
below, but it is worth pointing out here that many respondents saw the primary worth of such a framework lying in its ability to help explain the profession's scope to employers and to clients. The fact that the Global Capabilities Framework has been developed from global research and endorsed by the body representing the profession globally has added credence to their arguments for greater recognition and provided them with a body of evidence with which to claim legitimacy, seniority and professional territory.

\section{RQ2 What, if any, are the variations by region/culture and by stakeholder groups?}

The scope of this paper is to look at the global framework. Although the regional variations have been alluded to, the paper does not provide a detailed cross-country comparison using the individual country frameworks. Varying responses between academics and practitioners within and between countries will be explored elsewhere.

The differences in phrasing capabilities can be seen in Table 4 in the Findings. These suggest some variation by region and again the synthesising discussion in Stage 4 confirmed a degree of difference. Interestingly, more variety can be seen in what is included and excluded from each country framework, for example, many countries exhibit a strong emphasis on organisational interests, ethics is framed as 'on behalf of the organisation' (USA), or simply omitting a sense of external relationships (Singapore). Other countries particularly Argentina and South Africa - mention social contexts, needs and community demands under various capabilities. This clearly reflects both tensions and aspirations in countries that are experiencing degrees of change and transition and where the political and social context is volatile. This raises a question for future research - is there $a$ distinction between those regions that place public relations in a societal context and those that see it almost entirely as an organisational function? If so, what are the reasons for the societal or organisational emphasis?

Some of the omissions on the face of it appear surprising. For example, in Sweden there is no mention of ethics explicitly. However, it was clear from discussions with the lead researcher that this was strongly embedded in the professional association and was almost an assumed capability in the practice. 
In Spain there was a significant emphasis on the management of intangible assets, but a deeper investigation showed that this could be accommodated fully within the first capability, especially with the addition of 'values' to the statement: to align communication strategies with organisational purpose and values and within the sixth capability: to build and enhance organisational reputation.

In sum, although on the face of it the regional differences appeared small, they were important.

RQ3 How can such a framework(s) be of practical value for professional development, at individual, national, regional and global levels?

All but two of the partner countries addressed this question directly through focus group discussion and/or interviews. The UK team worked closely with a company of young entrepreneurs to produce software that allows users to assess individual and collective capabilities and set goals for a variety of time periods. This proved helpful in showing how the Global Capabilities Framework could be used as an interactive tool to plot both current and aspirational capabilities and enriched discussions as potential users could see the Framework 'come to life'. In addition Board members of the GA who represent 13 countries and leaders of other professional associations discussed the capabilities at two workshops held in London in December 2017 and in Oslo in 2018 and fed the results back to the research team.

The researchers were able to identify the following potential uses of the Global Capabilities Framework:

\subsection{Individual practitioners}

The framework will assist individuals assess their own performance in the capabilities they deem important, identifying both gaps and strengths. Practitioners commented that because of the way it was constructed, that is, it is independent of specialisms such as internal communication or financial public relations, it is populated with statements that would be relatively timeless (for example, 'communicate effectively across a full range of 
platforms and technologies'); and, because it is neutral of levels, there is flexibility to apply the statements to their own context. This degree of 'elasticity' would allow them to plan their future development in a more holistic way, looking at areas for development which may change because of, for instance, artificial intelligence, but where the principles of the capabilities such as facilitating relationships, building trust and providing valuable counsel would not change. Thus, the whole framework had a future orientation which they found helpful.

In addition, the CA approach encouraged them to look at their potential as practitioners and encouraged them to set goals which will enhance performance. Psychologically they found this more motivating than ticking off a raft of KSABs: the capability approach was seen to be about them realising their 'best selves' rather than passing a test, which competency frameworks can feel like.

As indicated earlier, practitioners also stated the Framework will be used to position the profession to internal and external groups, including potential employers, demonstrating its scope and how it adds value. Interestingly, a crucial gap, the case for more management and leadership capabilities training, can be made using the Framework.

The strength of the underpinning software was seen as two-fold: first, it provides a personal assessment and tool, and second, it will allow ready access to linked capability-building resources, for example, training, readings, webinars and mentoring opportunities. These resources will be provided by the in-country professional association.

\subsection{Team leaders/employers}

Practical uses for employers include: the ability to identify individual and team baseline capabilities, assess training and development needs, set individual and team expectations and through demonstrating a commitment to development, aid retention.

Specific utility was identified by leaders in using the tool for constructive appraisal, staff development and target setting. It was seen to be particularly powerful if the base assessments are done collaboratively between junior practitioners and their seniors both to arrive at a common understanding of where the baseline lay, but also as an opportunity to 
explore the breadth of the public relations role, the potential it offered and discussions about possible futures.

The software allows the results from a group of individuals to be collated and visually displayed thereby enabling current team, department or workforce strengths and weaknesses to be identified. This in turn can guide team development and succession planning and assist in individual hiring decisions. At a level of granularity, the Global Capabilities Framework can be of help in developing individual job descriptions.

In addition, given the software allows individuals and groups to record their development goals overtime, leaders are able to keep a dynamic overview, monitor on a regular basis and determine if adjustments need to be made depending on circumstances and staff changes.

\subsection{Educators}

The framework can be used as tool for curriculum development, review and approval with academic and professional courses mapping content against the capabilities. Thus, academic provision can be 'regularised' against an agreed Framework on a country by country and a global basis. Educators can also design content to enhance particular capabilities, such as addressing gaps between current performance and future requirements.

Educators have indicated that they intend to use the Global Capabilities Framework in teaching, not only to alert students to the breadth and depth of public relations roles, but also to prepare them for the world of work in practical career planning classes.

It could be used to ensure a level of consistency between curricula worldwide and hence facilitate student and staff exchanges, an area that has been fraught with practical difficulties because of equivalency issues.

In addition to the benefits and opportunities indicated by the three primary research populations, a clear role for the professional associations was identified as training provision standard-setters, training providers and accreditation bodies for academic institutions who 
would be required to demonstrate their courses were calibrated against the Global Capabilities Framework.

\section{Conclusions}

Overall, the two-year, nine-country research project suggests first, that there is a widely shared set of public relations and communication capabilities that help define the profession globally. Second, that there are minor, but significant, variations between countries' capability sets, particularly concerning the social role of public relations and in the use of terminology. Third, that individuals, professional bodies, employers and academics see the practical utility of the framework for managing personal, membership development, individual and team management, and educational provision respectively.

In summary, the research has produced outputs that have value and contribute to the field in two respects. First, a Global Capability Framework that fulfils the brief given by the GA: that it should offer practical value to affiliated professional bodies and their members, worldwide; reflect cultural and regional variations in public relations as a global profession; be forward looking in its approach; and meet academic standards for rigour.

Second, the research makes a contribution to theory building in two main ways. First, it demonstrates that rigour in thinking about a suitable research design, methodology and methods can also accommodate flexibility in application of those methods as long as the research questions are fully addressed and the resultant scientific limitations are acknowledged. It recognises that for global qualitative research projects in particular, differences in culture are important and that a slavish adherence to all specified methods in all circumstances can be a hindrance to discovering richness in responses. It might be argued that the strict scientific method should be applied, but the world of practice is not bounded by rationality alone and planned deviations can add value as long as the implications are recognised.

The second contribution to theory is the introduction of the CA to the field. It assists a move away from the largely instrumental offerings around competence and competency to a more holistic understanding of capability in public relations and communication 
management, one which acknowledges agency and potential, not one that is prescriptive and about current performance. As such, it is again more reflective of the real world where practitioners need and use different combinations of capabilities and at different levels of expertise as they move through varied careers where the requirement to be flexible and constantly developing will become even more important.

Jose Manuel Velasco Guardado, Chair of the Global Alliance has said, "The Global Capabilities Framework is one of the most significant projects that we have ever initiated. It is literally a game-changer for the profession." (Velasco Guardado, 2018)

\section{Limitations}

It is recognised that in allowing latitude on data collection methods to reflect cultural and contextual variations, the study prevents strict scientific comparisons. Given that the research design incorporated three data collection methods which were complementary and that that there did not appear to be large differences between the Delphi, survey and focus group results when all three methods were deployed, the research team are satisfied that the final results are representative.

It was a disappointment that the survey generated limited numbers of responses. However, despite differences in country size and data collection techniques, it compares well, at 1079 responses in nine countries, with similar studies such as the well-established European Communication Monitor which in 2018 collected 3,100 responses from 48 countries (Zerfass, Tench, Verhoeven, Vercic, \& Moreno, 2018).

Many, but not all of the participating countries are broadly located in developed or highly developed economies, some with decades of professional organisation and education. As more and less developed countries conduct capability research as the project is rolled out in the coming years, more differences may emerge. That will help to calibrate and provide nuance to the Global Capabilities Framework, which is designed to be dynamic and amenable to being regularly updated. 
Funding. The project was supported by the University of Huddersfield's University Research Fund for which the researchers and the Global Alliance are grateful.

Ethical approval: Ethical approval for this research was obtained from all participating Universities through their official institutional processes.

Notes

1. The authors recognise that the word 'profession' is contested and that there is considerable debate and scholarship about whether public relations is a profession, an occupational field, a craft or a para profession. We have decided to use the word profession in this paper because a descriptor has to be used and this appears to be most appropriate in this context. The research was prompted and supported by the Global Alliance, the UN recognised NGO which draws its membership from the professional associations (not trade associations) worldwide.

2. The Global Alliance is the worldwide confederation of professional associations in public relations and communication management. For more details, see https://www.globalalliancepr.org

3. The partner institutions in the project were: University of Huddersfield, UK; Lund University, Sweden; Singapore Management University, Singapore; University of Pretoria, South Africa; Universidad de Navarre, Spain; University of Oklahoma, USA; Mount Saint Vincent University \& McMaster University, Canada; RMIT University \& University of Curtin, Australia; Universidad Abierta Interamericana, Argentina.

4. The full capability framework and the country reports can be viewed at hud.ac/ect

\section{References}

Barney, J. B. (1997). Gaining and sustaining competitive advantage. Addison-Wesley: Reading, MA.

Bartram, D. (2004). Assessment in organisations. Applied Psychology, 53(2), 237-259.

Bartram, D. (2005). The Great Eight competencies: a criterion-centric approach to validation. Journal of applied psychology, 90(6), 1185.

Bartram, D. (2006). The SHL universal competency framework. SHL White Paper: Surrey, UK. Bates, R. (2007). Developing capabilities and the management of trust. In M. Walkern \& E. Unterhalter (Eds), Amartya Sen's capability approach and social justice in education (pp. 137-156). New York: Palgrave Macmillan. 
Brooke, B. \& Matthews, P. (2012). Paradigm Shift, Building a new talent management model to boost growth. Ernst \& Young. Retrieved from http//: www. ey. com/growingbeyond, 2.

Christensen, L.T., \& Cornelissen, J. (2011). Bridging corporate and organizational communication: review, development and a look to the future. Management Communication Quarterly, 25(3), 384 -414.

CIPD (Chartered Institute of Professional Development) (2017). Competence and competency frameworks. Retrived from https://www.cipd.co.uk/knowledge/fundamentals/people/performance/competenc $\mathrm{y}$-factsheet\#6385December 102018

Cosic, R., Shanks, G., \& Maynard, S. (2015). A business analytics capability framework. Australas. J. Inf. Syst. Australasian Journal of Information Systems, 19, S5-S19.

Cornelissen, J. (2017). Corporate Communication: A guide to theory and practice. London: Sage.

Dosi, G., \& Teece, D. J. (1998). Organizational competencies and the boundaries of the firm. In R. Arena \& C. Longhi (Eds.), Markets and organization (pp. 281-302). Berlin: Springer Science \& Business Media.

Edwards, L. (2018). Understanding Public Relations: Theory, culture and society. London: Sage.

Eraut, M., \& du Boulay, B. (2000). Developing the attributes of medical professional judgement and competence, Cognitive Sciences Research Paper 518, University of Sussex. Retrieved from http://users.sussex.ac.uk/ bend/doh/index.html

Fawkes, J., Gregory, A., Falkheimer, J., Gutiérrez-García, E., Halff, G., Rensburg, R., Sadi, G., Sevigny, A., Sison, M.D., Thurlow, A., Tsetsura, K., \& Wolf, K. (2018). A Global Capability Framework for the public relations and communication management profession. Global Alliance for Public Relations and Communication Management (GA) Research Report. Huddersfield, UK: University of Huddersfield. Retrieved from https://www.hud.ac.uk/media/assets/document/research/globalcapabilitiesinpublic relationsandcommunicationmanagementgcpr/global-capability-frameworkbrochure.pdf. December 6th 2018

Fraser, S. \& Greenhalgh, T (2001). Coping with complexity: Educating for capability. British Medical Journal, 323(7317), 799-803

Gangas, S. (2015). From agency to capabilities: Sen and sociological theory. Current Sociology, 64(1), 22-40.

Global Alliance (2016a). Global Body of Knowledge (GBOK). Retrieved from https://static1.squarespace.com/static/561d0274e4b0601b7c814ca9/t/56c1fb07598 27e4bccf4dc2a/1455553288468/KSABlist.pdf

Global Alliance (2016b). From the Global Capabilities Body of Knowledge (GBOK) to a global capabilities framework. Retrieved from https://static1.squarespace.com/static/561d0274e4b0601b7c814ca9/t/574ae46707 eaa010521f0d31/1464525936413/08 GBOK+Progress+report+\%26+global+capabiliti es+framework+May+2016.pdf, $6^{\text {th }}$ December 2018

Gregory, A. (2008). Competencies of senior communication practitioners in the UK: An initial study. Public Relations Review. 34(3), 215-223.

Gregory, A. (2012). Reviewing public relations research and scholarship in the $21^{\text {st }}$ century. Public Relations Review, 38(1): 1-4 
Hall, R. (1992). The strategic analysis of intangible resources. Strategic management journal, 13(2), 135-144.

Hallahan, K., Holzhausen,D., van Ruler, B., Vercic, D., \& Sriramesh, K. (2007). Defining strategic communication. International Journal of Strategic Communication, 1(1), 335

Heath, R.E., \& Gregory, A. (2015). Introduction: Defining strategic communication groundings, forewarnings, and calls to action. In Strategic Communication R.E. Heath \& A. Gregory Eds.), Sage Benchmarks in Communication. Vol.1. pp. xxxi - xxxvi. London: Sage.

ISO (2012). Quality management - Guidelines on people involvement and competence. Retrieved from https://www.iso.org/standard/46233.html

Jacobson, T. L. (2016). Amartya Sen's Capabilities Approach and Communication for Development and Social Change. Journal of Communication, 66(5), 789-810.

Kleine, D. (2011). The capability approach and the 'medium of choice': steps towards conceptualising information and communication technologies for development. Ethics and Information Technology, 13(2), 119-130.

Lester, S. (2014). Professional competence standards and frameworks in the United Kingdom. Assessment and Evaluation in Higher Education, 31(1), 707- 716

Lester, S. (2016). Communicating Professional Competence. London: Erasmus+ programme of the EU Stan Lester Developments.

Logeion (2012,February,17).Beroepsniveauprofielen[Joblevelprofiles]. Retrieved from http://www.logeion.nl/beroepsniveauprofielen.

Macnamara, J., Zefass, A., Adil, A. \& Lwin, M.O. (2018). Capabilities of PR profesionals for key activities lag: Asia-Pacific study show theory and practice gaps. Public Relations Review, 44(5), 56-70.

Manley, D., \& Valin, J. (2017). Laying the foundation for a global body of knowledge in public relations and communications management. Public Relations Review, 43(1), 56-70.

McCarthy, C. F., Kelley, M. A., Verani, A. R., St. Louis, M. E., \& Riley, P. L. (2014).

Development of a framework to measure health profession regulation strengthening. EPP Evaluation and Program Planning, 46, 17-24.

Mulder, M. (2001). Competence development-some background thoughts 1 . The Journal of Agricultural Education and Extension, 7(4), 147-158.

Nagarajan,R. \& Prabhu, R. (2015). Competence and capability: A new look. International Journal of Management, 6(6), pp. 7-11.

Nussbaum, M. (2002). Capabilities and social justice. International Studies Review, 4(2), 123135.

Nussbaum, M. C. (2000). Women and human development : the capabilities approach. Cambridge; New York: Cambridge University Press.

O'Connell, J., Gardner, G., Coyer, F., Gardner, G., \& Coyer, F. (2014). Beyond competencies: Using a capability framework in developing practice standards for advanced practice nursing. Journal of Advanced Nursing, 70(12), 2728-2735.

Pieczka, M. (2016). Making sense of competence frameworks in public relations and communication management: gaps in knowledge. Paper presented at the 66th International Ccommunication Association Annual Conference, Fukuoka, Japan.

Prahalad, C., \& Hamel, G. (1990). The Core Competence of the Corporation. Harvard Business Review, 68(3), 79-91. 
Rea, L. M. \& Parker, R. A. (1996). Designing and conducting survey research: A comprehensive guide. San Francisco, CA: Jossey-Bass Inc.

Robeyns, I. (2006). The Capability Approach in Practice. JOPP Journal of Political Philosophy, 14(3), 351-376.

Sen, A. (1993). Capability and Well-Being. In M.Nussbaum \& A. Sen (Eds.), The quality of life. (pp. 30-53) New York: Oxford University Press.

Sen, A. (1999). Development as freedom. New York: Knopf.

Sourani, A., \& Sohail, M. (2015). The Delphi method: Review and use in construction management research. International Journal of Construction Education and Research, 11(1), 54-76.

Stephenson, J. (1998). The concept of capability and its importance in higher education. In J. Stephenson \& M. Yorke (Eds.), Capability and Quality In Higher Education (pp. 1-13). London: Kogan Page.

Stephenson, J., \& Yorke, M. (2013). Capability and quality in higher education: Routledge.

Stewart, D. W., Shamdasani, P. N. \& Rook, D. W. (2007) Focus groups: Theory and practice. Sage publications: London.

Teece, D. J., Pisano, G., \& Shuen, A. (1997). Dynamic capabilities and strategic management. Strategic Management Journal, 509-533.

Tench, R., Zerfass, A., Verhoeven, P., Verčič, D., Moreno, A., \& Okay, A. (2013). Competencies and Role Requirements of Communication Professionals in Europe. Insights from quantitative and qualitative studies. ECOPSI Research Report. Leeds, UK: Leeds Metropolitan University

University of Huddersfield (2018). Global capabilities in public relations and communication management. REtyrieved from https://www.hud.ac.uk/about/schools/huddersfieldbusiness-school/research/gcpr/publications/

Velasco Guardado, J.M.(2018). Personal correspondence with authors.

Wakefield, R., \& Watson, T. (2014). A reappraisal of Delphi 2.0 for public relations research. Public Relations Review, 40(3), 577-584.

Walker, M., \& Unterhalter, E. (2007). Amartya Sen's capability approach and social justice in education. New York, NY: Palgrave Macmillan.

Watson,T. (2008). Public relations research priorities: a Delphi study, Journal of Communication Management, 12(2), 104-123

Winter, S. G. (2003). Understanding dynamic capabilities. Strategic Management Journal, 24(10), 991-995.

Zahra, S. A., Sapienza, H. J., \& Davidsson, P. (2006). Entrepreneurship and dynamic capabilities: a review, model and research agenda. Journal of Management Studies, 43(4), 917-955.

Zerfass, A., Tench, R., Verhoeven, P., Vercic,D. \& Moreno, A., (2018). European Communication Monitor 2018: Strategic communication and the challeneges of fake news, trust, leadership, work stress and job satisfaction. Results of a survey in 48 countries. Brussels: EACD/EUPRERA, Quadriga Media Berlin 